Available Online at https://akper-sandikarsa.e-journal.id

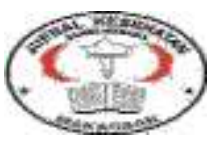

\author{
Jurnal Ilmiah Kesehatan \\ Sandi Husada
}

ISSN 2654-4563

Jurnal Ilmiah Kesehatan Sandi Husada

Vol.1,Issue, 1, pp. 1408-1410, Juni 2019

\title{
Research Article \\ STUDI KASUS PADA KELUARGA Tn.M YANG MENGALAMI HIPERTENSI DIKELURAHAN BAROMBONG KOTA MAKASSAR
}

\author{
${ }^{1}$ HARTATY, ${ }^{2}$ Maria Kurni Menga
}

12 Prodi DIII Keperawatan Sandi Karsa

\begin{tabular}{l}
\hline ARTICLE INFO \\
Article History: \\
Received April 2019 \\
Juni, 2019 Published online
\end{tabular}

Key Words: ABSTRAK

Tujuan pembangunan kesehatan menuju Indonesia sehat 2020 adalah meningkatkan kesadaran, kemauan dan kemampuan hidup sehat bagi setiap orang agar terwujud derajat kesehatan masyarakat yang optimal melalui terciptanya masyarakat bangsa dan negara Indonesia yang ditandai oleh penduduknya hidup dalam lingkungan dan prilaku yang sehat serta memiliki derajat kesehatan yang bermutu secara adil dan merata. Proses keperawatan keluarga Tn."M" dengan Ny."D" yang mengalami masalah Keperawatan 


\section{Pendahuluan}

Tujuan pembangunan kesehatan menuju Indonesia sehat 2020 adalah meningkatkan kesadaran, kemauan dan kemampuan hidup sehat bagi setiap orang agar terwujud derajat kesehatan masyarakat yang optimal melalui terciptanya masyarakat bangsa dan negara Indonesia yang ditandai oleh penduduknya hidup dalam lingkungan dan prilaku yang sehat serta memiliki derajat kesehatan yang bermutu secara adil dan merata. Salah satu wujud nyata pelaksanaan strategi ini maka ditetapkannya sasaran pembangunan kesehatan menuju Indonesia sehat 2020 yaitu perilaku hidup sehat. (Farid Afansa Moloek,2013).

Untuk menuju Indonesia sehat 2020 maka pemerintah meningkatkan mutu pelayanan kesehatan primer, terutama penyakit hipertensi karena memiliki angka prevalensi yang tinggi dan akibat jangka panjang yang ditimbulkan serta mempunyai konsekuensi tertentu. (Soeparman, $d k k, 2014$ ).

\section{Kajian Literatur}

\section{Pengertian Hipertensi}

a. WHO mengemukakan bahwa hipertensi terjadi bila tekanan darah diatas $160 / 95 \mathrm{mmHg}$

b. Smelttzer dan Bare (2002) mengemukakan bahwa hipertensi merupakaan tekanan darah persisiten atau terus menerus sehingga melebihi batas normal dimana tekanan sistolik diatas $140 \mathrm{mmHg}$ dan tekanan distolik diatas $90 \mathrm{mmHg}$.

c. Sharon, L. Rogen (1996) mengemukakan bahwa hipertensi adalah peningkatan abnormal pada tekanan sistolik $140 \mathrm{mmHg}$ atau lebih dan tekanan diastolik $120 \mathrm{mmHg}$.

d. Barbara Hearrison (1997) mengemukakan bahwa hipertensi adalah suatu keadan dimana terjadi peningkatan tekanan darah sistolik $140 \mathrm{mmHg}$ dan tekanan darah diastolik $90 \mathrm{mmHg}$ atau lebih.

Dari keempatdefenisi diatas dapat disimpulkan bahwa hipertensi adalah peningkatan tekanan darah yang abnormal dengan sistolik lebih dari $140 \mathrm{mmHg}$ dan diastolik lebih dari $90 \mathrm{mmhg}$.

Pada umumnya hipertensi tidak mempunyai penyebab yang spesifik. Hipertensi tejadi sebagai responpeningkatan cardiac output atau peningkatan tekanan darah perifer. Namun ada beberapa faktor yang mempengaruhi terjadi hipertensi:

a. Genetik

Respon nerologi terhadap stress atau kelainan ekskresi atau transport

b. Obesitas

Terkait dengan level insulin yang tinggi mengakibatkan tekanandarah meningkat.

c. Stress lingkungan

Berdasarkan penyebabnya hipertensi dibagi menjadi 2 golongan yaitu: (Lany Gunawan, 2001)

Mekanisme yang mengontrol konstriksi dan relaksasi pembuluh darah terletak dipusat vasomotor, pada medula diotak.
Dari pusat vasomotor bermula pada saraf simpatis yang berlanjut kebawah korda spinalis dan keluar dari kolumna medulla spinalis ganglia simpatis toraks da abdomen. Rangsangan pusat vasomotor dihantarkan dalam implus yang bergerak kebawah melalui sistem saraf simpatis ganglia simpatis. Pada titik ini, neuron preganglion melepaskan asetilkolin, yang akan merangsang serabut saraf pasca ganglion kepumbuluh darah ke pumbuluh darah, dimana dengan dilepaskannya noreepineprin mengakibatkan konstriksi pembuluh darah. Berbagai faktor seperti kecemasan dan ketakutan dapat mempengaruhi respon pembuluh darah terhadap rangsang vasokontriksi. Individu dengan hipertensi sangat sensitif terhadap norefineprin meskipun, tidak diketahui dengan jelas mangapa hal tersebut bisa terjadi.

Pada saat bersamaan dimana saraf simpatis merangsang pembuluh darah sebagai respon rangsang emosi, kelenjar adrenal juga terangsang, mengakibatkan tambahan aktivatas vasokontriksi. Korteks adrenal mensekresi kortisol dan steroid lainnya, yang dapat memperkuat respon vasokonstiktor pembuluh darah. Vasokonstriksi yang mengakibatkan penurunan aliran keginjal menyebabkan pelepasan renin. Renin merangsang pembentukan angitensin I yang kemudian diubah menjadi angiotensin II, suatu vasokonstiktor kuat, yang pada gilirannya merangsang sekresi aldosteron oleh korteks adrenal. Hormon ini menyebabkan retensi natrium dan air oleh tubulus ginjal menyebabkan peningkatan volume intra vaskuler. Semua faktor ini cenderung mencetuskan keadan hipertensi.

Untuk pertimbangan gerentology, perubahan struktural dan fungsional pada sistem pembuluh darah perifer bertanggung jawab pada perubahan tekanan darah yang terjadi pada usia lanjut. Perubahan tersebut meliputi aterosklerosis, hilangnya elastis jaringan dan penurunan dalam relaksasi otot polos pembuluh darah, yang pada gilirannya menurunkan kemampuan distensi dan daya renggang pembuluh darah. Konsekuensinya, aorta dan arteri besar berkurang kemampuannya dalam mengkomodasi volume darah yang dipompa oleh jantung (volume sekuncup), yang mengakibatkan penurunan curah jantung dan peningkatan tahanan perifer (Brunner dan Suddarth, 2002).

\section{Metode Penelitian}

Desain penelitian yang digunakan adalah metode studi kasus karena berujuan untuk menggambarkan keadaan atau status fenomena. Dalam hal ini peneliti hanya ingin mengetahui hal-hal yang berhubungan dengan keadaan sesuatu. Populasi, adalah keseluruhan subjek yang diteliti (Arikunto, 2010). Populasi pada penelitian ini adalah semua lansia yang berada di wilayah kerja puskesmas kampala sinjai 50 orang. Sampel, adalah sebagian atau 
wakil populasi yang diteliti (Arikunto, 2010). cara pengambilan sampel dengan menggunakan purfosive sampling yaitu pengambilan data secara acak sesuai dengan kriteria ekslusi dan inklusi.

Hasil

Dalam pengkajian keperawatan, penulis memperoleh pengalaman nyata tentang pengkajian dengan melakukan pendekatan interpersonal terhadap keluarga sedangkan perencanaan disusun berdasarkan tingkat pengetahuan, kemampuan dan sumber/fasilitas yang dimiliki dan dapat dijangkau oleh keluarga.

Dalam penyusunan perumusan masalah keperawatan keluarga, penulis memperoleh pengalaman nyata tentang penerapan asuhan keperawatan.

Dalam penyusunan rencana asuhan keperawatan keluarga, penulis memperoleh pengalaman nyata tentang penerapan asuhan secara langsung pada keluarga binaan.

Dalam pelaksanaan asuhan keperawatan, penulis menggunakan ilmu keperawatan masyarakat serta didukung oleh program masyarakat dari departemen kesehatan. Penulis membina kerjasama yang baik dalam melakukan intervensi yang telah ditetapkan selama tiga hari bersama dengan keluarga untuk memecahkan dan mengatasi masalah dengan membuat perencanaan, melaksanakan kegiatan pemerataan dan mengatasi masalah dengan membuat perencanaan, melaksanakan kegiatan, pemecahan masalah dan evaluasi.

Dalam melakukuan evaluasi terhadap intervensi yang sudah dilaksanakan, penulis memperoleh pengalaman nyata tentang hasil yang diperoleh. Ada beberapa kesenjangan yang terjadi dan beberapa hambatan yang diperoleh dimana telah di bahas pada bab sebelumnya.

\section{Kesimpulan}

Pada perawatan keluarga hendaknya menggunakan pendekatan yang sistematis untuk mengindentifikasi masalah kesehatan secara tepat. Perlu adanya peningkatan informasi yang diberikan oleh petugas kesehatan guna meningkatkan pemahaman keluarga dan masyarakat terhadap suatu penyakit yang dialami dan masalah kesehatan yang terkait dengan kehidupan orang banyak, melalui preventif, dan promosi kesehatan.

Kepada keluarga setelah dilakukan pembinaan agar hendaknya dapat merubah perilaku, pengetahuan dan pemahaman yang berhubungan dengan kesehatan lingkungan sehingga tercipta kondisi-kondisi yang memungkinkan keluarga untuk hidup sehat dan dapat mencegah atau memperbaiki masalah-masalah kesehatan dalam ruang lingkupnya sebagai unit pelayanan kesehatan.

\section{Literatur}

Bambang Dwiloka, Rati Riana (2005), “Tehnik Menulis Karya Ilmiah", Rineka Cipta, Jakarta.

Brunner \& Suddarth, 2002, Keperawatan Medikal Bedah, Edisi 8, EGC, Jakarta.

Corwin Elizabeth. J, 2001; Buku Saku Patofisiologi ; EGC, Jakarta.

Dinas Kesehatan Provinsi Sulawesi Selatan, 2018, Profil Kesehatan Sulawesi Selatan. Makassar

Dinas Kesehatan Kota Makassar 2018, Profil Kesehatan Kota Makassar.

Dinas Kesehatan Kota Makassar 2018, 10 Penyakit Utama di Kota Makassar

Fagan Toby, 2002, Cardiovaskular System 2nd edition, Mosby, Totenham.

Slamet Suyono, (2001), Ilmu Penyakit Dalam, Edisi 3 Jilid 2, Balai Penerbit, FK UI, Jakarta.

Manjoer, Triyanti, 2001. Kapita Selekta Kedokteran, Edisi 3 Jilid 2, 2001.

Muh. Nazir, Ph.D, 2003, “Metode Penelitian”, Ghalia Indonesia, Jakarta.

Marliani Lili, Tantan S, 2007, “100 Question \& Answers: Hipertensi”, elexmedia komputindo, Jakarta.

Stein, Jay H, (2001); Panduan Klinik ilmu Pemyakit Dalam, Edisi 3, EGC,Jakarta. 